\title{
Long-term anticoagulation with fondaparinux in a patient with a mechanical heart valve
}

\author{
Michael Nagler • Michael Haslauer • \\ Walter A. Wuillemin
}

Received: 7 December 2010 /Accepted: 14 December 2010/Published online: 5 January 2011

(C) Springer-Verlag 2010

\begin{abstract}
Dear Editor,
Despite recent advances in anticoagulation therapy, there are regular situations in clinical practice which are inadequately covered by current guidelines. These include situations such as obesity and long-term therapy, particularly if vitamin $\mathrm{K}$ antagonists (VKA) and/or heparin derivatives are inappropriate. These situations have rarely been the aim of randomised controlled trials. We present a case of successful long-term treatment with fondaparinux in a patient with a mechanical heart valve, obesity and concomitant therapy with aspirin and discuss available data in these situations.

A 63-year-old male patient with obesity underwent aortal valve replacement with a mechanical prosthesis because of aortal stenosis. Anticoagulation with VKA was started. Six weeks postoperatively, he presented with lifethreatening bleeding. Investigations revealed factor IX propeptide mutation, which made anticoagulation with VKA impossible. This rare condition causes a nearly complete absence of factor IX during therapy with VKA, even in the presence of a mild vitamin K deficiency [1]. Therapy with low-molecular-weight heparin (LMWH) resulted in lumps at the puncture site. Failure of absorption
\end{abstract}

M. Nagler $\cdot$ W. A. Wuillemin $(\bowtie)$

Division of Haematology and Central Haematology Laboratory,

Luzerner Kantonsspital,

CH-6000 Lucerne 16, Switzerland

e-mail: walter.wuillemin@ksl.ch

\section{Haslauer}

GlaxoSmithKline AG,

CH-3053 Münchenbuchsee, Switzerland

W. A. Wuillemin

University of Berne,

CH-3000 Berne, Switzerland could be seen in a gradual decrease in drug concentration measured as anti-Xa level (initially $0.9-1.0 \mathrm{U} / \mathrm{ml}$, reduced to $0.45-0.5 \mathrm{U} / \mathrm{ml}$ ), despite increasing the dose. This adverse effect was shown with dalteparin, enoxaparin and nadroparin. Anticoagulation was therefore started with fondaparinux. Due to obesity (BMI, $36 \mathrm{~kg} / \mathrm{m}^{2}$ ), we administered $10 \mathrm{mg}$ once daily sc. During the next 30 months, stable drug concentrations measured as anti-Xa of about $1.0 \mu \mathrm{g} / \mathrm{ml}$ were observed. D-dimers, measured as a degree of coagulation activation, were always below $220 \mathrm{ng} / \mathrm{ml}$. Regular controls revealed no clinical signs or symptoms of thromboembolic complications, and in particular, no neurological deficits. Computed tomography of the head as well as echocardiography did not reveal any thromboembolic complications. The patient did not experience any bleeding. Due to additional risk factors for thromboembolism, $100 \mathrm{mg}$ aspirin was added to the therapy.

A high bioavailability, long elimination half life, very low intra- and intersubject variability and lack of relevant drug interactions suggest good efficacy and safety during long-term treatment [2-4]. This was confirmed in a phase III trial in the treatment of superficial vein thrombosis with fondaparinux $2.5 \mathrm{mg}$ for 45 days [5] and in one prospective observational study reported on patients treated with a therapeutic dose of fondaparinux $(7.5 \mathrm{mg})$ for 90 days because of deep vein thrombosis or pulmonary embolism [6]. Our report described above is by far the longest reported therapy with fondaparinux (more than 30 months up to now).

Two different models, an in vitro experiment and ex vivo rabbit model with artificial mechanical heart valves, showed comparable thrombosis rates as seen with UFH or LMWH [7, 8]. To the best of our knowledge, the patient described above is the first case report of successful longterm anticoagulation with fondaparinux in a patient with mechanical heart valve. 
In conclusion, our case report confirms available data and shows that it is possible to conduct long-term anticoagulation with fondaparinux in combination with aspirin in a patient with a mechanical heart valve and obesity.

\section{Financial support None.}

Conflict of interest Dr. Wuillemin reports receiving lecture honoraria and consulting fees from Bayer, GlaxoSmithKline, Pfizer and SanofiAventis. Dr. Haslauer is an employee of GlaxoSmithKline. There is no other potential conflict of interest relevant to this article.

\section{References}

1. Bestmann L, Zuger M, Oldenburg J, Buhler D, Maly FE (2001) Coagulation factor IX propeptide mutations causing coumarin hypersensitivity: identification of female alanine-10 valine heterozygotes. Thromb Haemost 85(3):567-568

2. Donat F, Duret JP, Santoni A, Cariou R, Necciari J, Magnani H, de Greef R (2002) The pharmacokinetics of fondaparinux sodium in healthy volunteers. Clin Pharmacokinet 41(Suppl 2):1-9
3. Mant T, Fournie P, Ollier C, Donat F, Necciari J (2002) Absence of interaction of fondaparinux sodium with digoxin in healthy volunteers. Clin Pharmacokinet 41(Suppl 2):39-45

4. Ollier C, Faaij RA, Santoni A, Duvauchelle T, van Haard PM, Schoemaker RC, Cohen AF, de Greef R, Burggraaf J (2002) Absence of interaction of fondaparinux sodium with aspirin and piroxicam in healthy male volunteers. Clin Pharmacokinet 41 (Suppl 2):31-37

5. Decousus H, Prandoni P, Mismetti P, Bauersachs RM, Boda Z, Brenner B, Laporte S, Matyas L, Middeldorp S, Sokurenko G, Leizorovicz A (2010) Fondaparinux for the treatment of superficial-vein thrombosis in the legs. N Engl J Med 363(13):1222-1232

6. Shetty R, Seddighzadeh A, Parasuraman S, Vallurupalli NG, Gerhard-Herman M, Goldhaber SZ (2007) Once-daily fondaparinux monotherapy without warfarin for long-term treatment of venous thromboembolism. Thromb Haemost 98(6):1384-1386

7. Schlitt A, Buerke M, Hauroeder B, Peetz D, Hundt F, Bickel C, Schaefer I, Meyer J, Rupprecht HJ (2003) Fondaparinux and enoxaparin in comparison to unfractionated heparin in preventing thrombus formation on mechanical heart valves in an ex vivo rabbit model. Thromb Haemost 90(2):245-251

8. Schlitt A, Hamilton K, Maegdefessel L, Dahm M, Theis C, Eichler M, Brockmann O, Steinseifer U, Hauroeder B, Hitzler WE, Rupprecht HJ (2006) Comparison of fondaparinux, low molecular-weight heparin and unfractionated heparin in preventing thrombus formation on mechanical heart valves: results of an in-vitro study. J Heart Valve Dis 15(6):809-814 